\title{
Deriving a climate temperature record from satellite data
}

\section{Donglian Sun}

Data from the Geostationary Operational Environmental Satellite series is analyzed to yield information about land surface temperature.

Temperatures at the Earth's surface are important for the study of global warming. Typically, global temperature change is assessed by in situ surface air temperature (SAT) measurements at $2 \mathrm{~m}$ height at weather stations. The diurnal temperature range (DTR) is also an important index of climate change. ${ }^{1-5}$ Until recently, most information on DTR also came from SATs, based on station observations. Strong diurnal and seasonal cycles are identified in SAT. ${ }^{6,7}$ However, weather stations are usually located in relatively densely populated regions where anthropogenic impacts may affect measurements, and thus the temperature record may not be representative of global change. Moreover, station observations are sparse and unevenly distributed, and they suffer from differences in elevation and time of observation. ${ }^{8}$ The use of satellite-derived data could contribute to a globally consistent measurement. ${ }^{9}$

Most surface temperature retrievals from satellites are based on polar orbiters. ${ }^{10-15}$ Surface temperature, especially land surface temperature (LST), has a strong diurnal cycle, which cannot be captured at the temporal resolution (approximately two views per day) of such satellites. Only two points in the cycle are measured, and the sampling is neither continuous nor homogeneous because the exact timing of these two points will drift. The drift in local equatorial crossing time of the US National Oceanic and Atmospheric Association (NOAA) series of polar-orbiting satellites, ${ }^{16}$ for example, leads to a non-climatic trend in surface temperature, which degrades the usefulness of LST measurements from those satellites. Geostationary satellites, on the other hand, provide good diurnal coverage, making them attractive for deriving information on the diurnal LST cycle. ${ }^{17-19}$

One of our current projects is to derive long-term climate surface temperature records from the NOAA Geostationary Operational Environmental Satellite (GOES) series. In addition to problems with maintaining consistent calibration over time, changes in GOES imager channels are also a big concern.

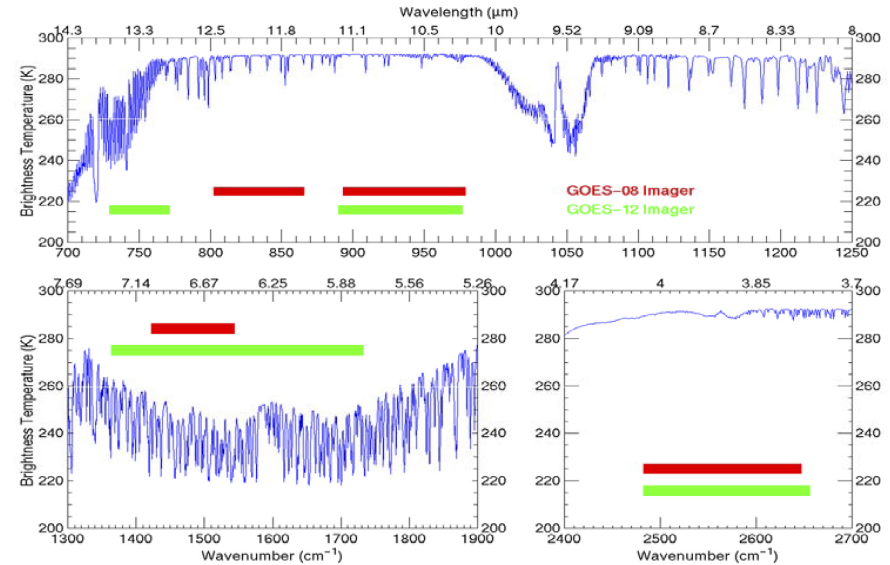

Figure 1. The GOES-8 (red) and GOES-12 (green) bands.

GOES-8 has the traditional split-window channels that can be used for atmospheric correction. We have worked extensively with algorithm development and surface temperature retrieval from GOES-8, and its surface skin temperature algorithm is relatively mature. However, the GOES M (12) through Q series satellites lack the split-window channels that would enable the evaluation of LST based on differential atmospheric (water vapor) absorption in two infrared channels. ${ }^{18}$ (Figure 1 compares the GOES- 8 and GOES-12 bands.) Therefore, I proposed a two-channel algorithm using the characteristics of the midinfrared channel $(3.9 \mu \mathrm{m})$ with less atmospheric absorption, and one channel $(11 \mu \mathrm{m})$ plus a water-vapor correction algorithm. Using this algorithm, surface temperature can be derived from the current GOES-M and GOES-Q data, as shown in Figure 2.

The evaluation of surface temperature retrievals from satellites has been difficult, since satellites measure skin temperature at the pixel level, while global-scale ground observations are from shelters at point scale. Due to the lack of ground observations, ${ }^{17,18}$ I attempted to use various available surface observations, directly and indirectly related to surface skin temperature, including atmospheric radiation measurement, 


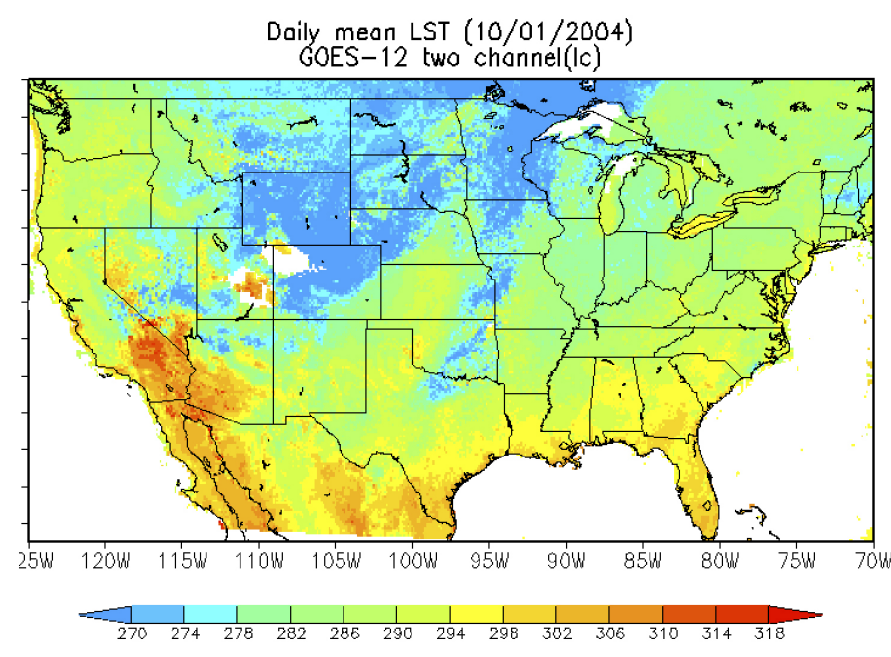

Figure 2. LST derived from the GOES-12 observations.

Surface Radiation Network data, and Mesonet observations, to evaluate LST values retrieved from GOES satellites. These evaluations indicate that the results shown in Figure 2 provide a reasonably accurate record of surface temperature.

My colleagues and I are in the process of generating a consistent surface temperature record from the GOES series satellites.

\section{Author Information}

\section{Donglian Sun}

George Mason University

College of Science, Geography and Geoinformation Science Department

Fairfax, VA

\section{References}

1. T. R. Karl, G. Kukla, and J. Gavin, Decreasing diurnal temperature range in the United States and Canada from 1941-1980, J. Clim. Appl. Meteorol. 23, pp. 14891504,1984

2. T. R. Karl, P. D. Jones, R. W. Knight, G. Kukla, N. Plummer, V. Razuvayev, K. P. Gallo, J. Lindseay, R. J. Charlson, and T. C. Peterson, A new perspective on recent global warming, Bull. Am. Meteorol. Soc. 74, pp. 1007-1023, 1993.

3. D. R. Easterling, T. C. Peterson, and T. R. Karl, On the development and use of homogenized climate datasets, J. Clim. 9, pp. 1429-1434, 1997.

4. K. Braganza, D. J. Karoly, and J. M. Arblaster, Diurnal temperature range as an index of global climate change during the twentieth century, Geophy. Res. Let. 31, Art. No. L13217 (13), 2004.

5. Intergovernmental Panel on Climate Change in Climate Change, J. T. Houghton, Y. Ding, D. J. Griggs, M. Noguer, P. J. van der Linden, X. Dai, K. Maskell, and C. A. Johnson (eds.), The Scientific Basis, Cambridge Univ. Press, Cambridge, U.K., 2001.

6. K. Y. Vinnikov, A. Robock, and A. M. Basist, Diurnal and seasonal cycles of trends of surface air temperature, J. Geophys. Res. 107 (D22), p. 4641, 2002. doi:10.1029/2001JD002007

7. K. Y. Vinnikov, A. Robock, N. C. Grody, and A. Basist, Analysis of diurnal and seasonal cycles and trends in climatic records with arbitrary observation times, Geophys. Res. Lett. 31, p. L06205, 2004. doi:10.1029/2003GL019196
8. T. C. Peterson, Assessment of urban versus rural in situ surface temperature in the contiguous United States: No difference found, J. Clim. 16 (18), pp. 2941-2959, 2003.

9. K. P. Gallo, T. W. Owen, and D. R. Easterling, Temperature trends of the U.S. historical climatology network based on satellite-designated land use/land cover, J. Clim. 12 (5), pp. 1344-1348, 1999.

10. F. Becker and Z. L. Li, Toward a local split window method over land surface, Int'1 J. Remote Sens. 11, pp. 369-393, 1990.

11. F. Becker and Z. L. Li, Surface temperature and emissivity at various scales: Definition, measurement and related problems, Remote Sens. Rev. 12, pp. 225-253, 1995.

12. Z. Wan and J. Dozier, A generalized split-window algorithm for retrieving landsurface temperature from space, IEEE Trans. Geosci. and Remote Sens. 34, pp. 892905, 1996.

13. Z. Wan and Z.-L. Li, A physics-based algorithm for retrieving land-surface emissivity and temperature from EOS/MODIS data, IEEE Trans. Geosci. and Remote Sens. 35 (4), pp. 980-996, 1997.

14. Z. Wan, Y. Zhang, Q. Zhang, and Z. Li, Validation of the land surface temperature products retrieved from Terra Moderate Resolution Imaging Spectroradiometer data, Remote Sens. of the Environ. 83, pp. 163-180, 2004.

15. Y. Yu, J. L. Privette, and A. Pinheiro, Evaluation of Split-Window Land Surface Temperature Algorithms for Generating Climate, IEEE Trans. Geosci. and Remote Sens. 46 (1), pp. 179-192), 2008.

16. A. Ignatov, I. Laszlo, E. D. Harrod, K. B. Kidwell, and G. P. Goodrum, Equator crossing times for NOAA, ERS and EOS sun synchronous satellites, Int'1 J. Remote Sens. 25 (23), pp. 5255-5266, 2004.

17. D. Sun and R. T. Pinker, Estimation of land surface temperature from a Geostationary Operational Environmental Satellite (GOES-8), J. Geophys. Res. 108 (D11), p. 4326, 2003. doi:10.1029/2002JD002422

18. D. L. Sun, R. T. Pinker, and J. B. Basara, Land surface temperature estimation from the next generation of Geostationary Operational Environmental Satellites: GOES M-Q, J. Appl. Meteorol. 43, pp. 363-372, 2004.

19. D. L. Sun, R. T. Pinker, and M. Kafatos, Diurnal temperature range over the United States: A satellite view, Geophys. Res. Lett. 33, p. L05705, 2006. doi:10.1029/2005GL024780 